\title{
La vejez y el género en las telenovelas de mayor audiencia. Argumentos de una propuesta para una telenovela sobre envejecimiento activo a través del entretenimiento educativo
}

\section{Old age and gender in popular soap operas. Arguments for a proposal of a soap opera on active aging through educational entertainment}

Recibido: 30/07/2020

Aceptado: 02/11/2020

Publicado: 30/11/2020
Sandra Leal Larrarte

saleal@uniquindio.edu.co https://orcid.org/0000-0003-1526-7413

Universidad del Quindío (Colombia)

Martha Estela Pérez García meperez@uacj.mx https://orcid.org/0000-0003-0007-1418 Universidad Autónoma de Ciudad Juárez (México)

Lilia Inés López Cardozo liliai@uniquindio.edu.co https://orcid.org/0000-0002-6546-4661 Universidad del Quindío (Colombia)

Resumen: En la literatura sobre envejecimiento se escucha hablar del envejecimiento activo y en la literatura feminista se dialoga sobre los derechos e igualdad de género. De acuerdo con Sabido \& Jara (1989) y Bandura (1973), en los medios de comunicación (en particular las telenovelas) se multiplican 
los estereotipos negativos sobre la mujer y sobre las personas mayores. Apoyados en la propuesta de análisis de telenovelas de Sabido \& Jara (1989), se toman los conceptos de "educación" y "entretenimiento" para proponer no solo una manera de reconocer cómo enseñan las telenovelas, sino de cómo se pueden aprovechar para promocionar conductas dentro de la población. Asimismo, a través de estos conceptos se analizó la imagen que las telenovelas mexicanas y colombianas proyectan de los adultos mayores y, en especial, de las mujeres mayores, con el propósito de darle la oportunidad a este sector social de proponer cómo quieren ser representados en las telenovelas.

Palabras clave: Telenovela, Educación, Adulto mayor, Estudios de género.

Abstract: The literature of aging explores the deterioration of the human body, while feminist literature explores the problems of gender equality. According to Sabido \& Jara (1989) and Bandura (1973), the media, particularly soap operas, tend to use stereotypes that portray women and the elderly population negatively. Sabido \& Jara (1989) use the concepts of education and entertainment to unveil how telenovelas teach societal behavior, allowing a path for social discrimination towards them. Through these concepts, the researchers have demonstrated how the Mexican and Colombian telenovelas negatively portrayed the elderly people, especially women. Such analysis was not done in vain, as it had the purpose of giving agency to the elderly by allowing them to have to power of how they want to be represented in soap operas.

Key words: Soap opera, Education, Older adults, Gender studies.

\section{Introducción}

La historia de la telenovela se inicia en los años de 1970, principalmente con argumentos adaptados de libros de autores latinoamericanos. Estas producciones (insertadas dentro del melodrama) siempre han llamado la atención y por largo tiempo las telenovelas han sido las "reinas del rating", salvo en la primera parte del siglo XXI que han sido superadas por los reality shows. No obstante, existen (dentro de la tradición novelesca) algunas que, por la calidad de su producción o su tema, innovaron lo suficiente como para quedar ancladas en el recuerdo. Algunas alcanzan ratings fabu- 
losos, capaces de parar un país solo para que vean el capítulo, y la principal razón es porque ellas recogen la idiosincrasia local y le dan identidad a la población latinoamericana.

En la historia de las telenovelas se tienden a mencionar dos: "La esclava Isaura" (Brasil, 1976) y "Yo soy Betty la fea" (Colombia, 1999). La primera dio a conocer una etapa de la historia del Brasil, en un periodo en que la democracia estaba en duda. Bajo el disfraz de la esclavitud, hizo reflexionar a los televidentes sobre las violaciones a los derechos humanos cometidas durante el gobierno militar. "Yo soy Betty la fea", por su parte, le permitió a los adaptadores y a los televidentes reconocerse en un mundo centrado en la apariencia, la estética y el concepto de riqueza, según el esquema social de cada país.

Una característica fácil de identificar (en este formato televisivo) es la capacidad que tiene de reconocer los sentires del vaivén social e histórico del momento en que se desarrolla. Esa es la razón por la que los gobiernos, así como las entidades dedicadas al desarrollo de las comunidades, lo eligen para educar o fortalecer conductas a través del edu-entretenimiento, puesto que una de sus principales virtudes es darle no solo rostro sino voz a las poblaciones más marginadas.

No obstante, hay temas que son poco tratados o que relativizan la discriminación que por siglos se ha naturalizado, como es el caso de los adultos mayores y de las mujeres: grupos que son representados de manera desigual, invitando al público a reconocerlos como seres inferiores dignos de lástima o deslegitimándolos al burlarse de ellos.

Es obvio que, en más de cincuenta años de historia de la telenovela, el tema de las personas mayores se ha abordado de diferentes maneras y con diferentes efectos. Tampoco es raro que en cada telenovela producida haya al menos un adulto mayor, puesto que su presencia es una realidad que no se puede ignorar. Incluso, algunas de estas historias han tocado el tema de la vejez, más específico de la mujer en la vejez, como es el caso de telenovelas como "La abuela" (1979) y "Señora Isabel" (1993), pero el distanciamiento temporal de estas dos novelas da a entender el poco interés que despierta la población mayor entre las productoras. 


\section{Demografía de la vejez y el género}

Los resultados finales del censo del año 2018 trajeron a los colombianos varias sorpresas (DANE, 2018). En primer lugar, somos menos de los que pensábamos (se estimaba una población de casi 50 millones de habitantes y sólo somos 45.5 millones), vivimos más solos (los hogares conformados por una sola persona pasaron del 14\% en el 2005 al 19\% en el 2018) y somos más viejos (en el 2005 el 6.5\% de los colombianos superaba los 60 años, ahora son el 9.25\%).

Igual sucede en México: en el 2015 había 12 millones de personas mayores de 60 años. Eso quiere decir, que alrededor del 10,3\% de la población mexicana es mayor, de los cuales más de la mitad son mujeres. Un dato especialmente significativo si se tiene en cuenta la gran cantidad de actos violentos contra la mujer, que ocurren en dicho país (INEGI, 2015).

En cuanto al tema de la violencia de género, América Latina es una de las regiones más violentas del mundo: 14 de los 25 países en que se cometen más feminicidios son latinoamericanos. Nada más en México (en el 2016) se cometieron 2000 feminicidios y en Colombia 400 mujeres asesinadas en razón de su género (CNN Chile, 2018). El problema se recrudece al saberse que en los últimos cuatro años los feminicidios aumentaron en un $111 \%$ en México (Infobae, 2019). De acuerdo con cifras de la Organización Mundial de la Salud (OMS), una de cada diez personas mayores ha sido víctima de malos tratos, es por ello importante destacar el alto índice de maltrato hacia este sector de la población (citado en INPAM, 2019).

En el caso de las mujeres mayores los abusos se acentúan, ya que se encuentran en alto grado de vulnerabilidad por sufrir desatenciones de la familia, de la comunidad y de las instituciones. Estos actos afectan la integridad física, emocional y la capacidad de tomar decisiones.

El 45\% de las mujeres de 60 años o más declaró haber sufrido violencia por parte de su pareja o expareja a lo largo de su vida.

El tipo de violencia ejercida por su pareja con más alto porcentaje es la emocional, puesto que $90 \%$ de las adultas mayores declaró haber sido víctima de esta forma de agresiones, entre las que se encuentra: $62 \%$ dejarles de hablar; 52,2\% ignorarlas, no tomarlas en cuenta o no brindarles cariño y 48,3\% avergonzarlas, menospreciarlas o humillarlas. 
... Las investigaciones realizadas sobre el tema han demostrado que las mujeres de cualquier edad están expuestas a ser violentadas, pero en el caso de las que se encuentran en una etapa mayor, su situación las hace más susceptibles debido a la disminución de sus capacidades físicas, por padecer enfermedades crónico degenerativas, por tener bajo poder adquisitivo (por haber sido "amas de casa"), quedar viudas o solas, o por tener que vivir con sus hijos. (FIAPAM, 2014)

Como se puede apreciar, género y vejez son dos temas que no se pueden separar: son transversales a todas las acciones y raciocinios humanos, pero son igualmente desconocidos para las comunidades que han aceptado sus desigualdades y problemas como situaciones normalizadas. Por eso resulta importante analizar cómo se representa tanto la vejez como la desigualdad de género en las telenovelas latinoamericanas, teniendo en cuenta que estos dramas televisivos recogen las sensaciones y situaciones predominantes de las comunidades de donde se desprenden sus historias.

Para bien o para mal, estos melodramas se han convertido en el plato principal del menú televisivo en Latinoamérica, donde ocupan el segundo lugar entre los programas más vistos. El fútbol soccer ocupa el primer lugar, mientras que las películas, el tercero. Sin embargo, se puede elevar a las telenovelas sin problema al primer lugar de audiencia, debido que la mantienen cautiva de manera continua y creciente por un total de horas muy superior al de los otros formatos (Lizaur, 2014).

En ese sentido, se requieren propuestas que enriquezcan el sentido social de las telenovelas y que sean capaces de incluir a grupos marginados. Sin embargo, su labor más difícil está en desnaturalizar aquellas acciones que, por generaciones, se han transmitido como culturalmente aceptadas (machismo y estigmatización por edad).

\section{Telenovelas y entretenimiento educativo (EE)}

La telenovela es un drama sentimental que se construye alrededor de un conflicto, donde la tensión es el eje central de cada historia y su meta principal es alcanzar el final feliz tan ansiado en que cada personaje recibe lo que merece (Lizaur, 2014). Su estructura se compone de una historia (regularmente una 
"fábula rosa") que se entrelaza con el juego de las clases sociales. Los sujetos de la trama se distinguen por el color de piel, arreglo personal y vestuario. La piel morena suele representar "precariedad", "pobreza" y "fracaso"; en cambio, la piel blanca representa "poder", "riqueza" y "éxito". Desde la primera historia transmitida en la televisión mexicana (1957) y en la colombiana (1975) hasta la actualidad, se presentan tramas muy parecidas, sobre todo en el marcaje de los roles de género. Según Lizaur (2014), son un cúmulo de historias rosas que repiten y mantienen contenidos lineales que no exigen un proceso de reflexión de la teleaudiencia.

Tras un estudio que se realizó a 26 telenovelas latinoamericanas (Medina \& Barrón, 2010), se concluye que las tramas tienden a ser repetitivas, estereotipadas y melodramáticas. Las audiencias caen en la magia de historias de lucha de clases, parejas que buscan el amor y traspasan múltiples problemas, causados por la maldad de los personajes que no los quieren ver unidos. De esta forma, las telenovelas constituyen un enclave para la producción audiovisual en Latinoamérica, no sólo por el peso que tienen en el mercado de la televisión, sino también por el papel que juegan en la representación de los valores culturales de la audiencia local (Medina \& Barrón, 2010).

Por su parte, Martín-Barbero \& Muñoz (1992) sostienen que las telenovelas tienen una relación directa con las idiosincrasias. En México los dramas son maniqueos, en Brasil las historias se desenvuelven en contexto realistas y en escenarios fastuosos; las teleseries colombianas guardan similitudes con las brasileñas porque suelen representar historias reales. Medina \& Barrón (2010) afirman que estas telenovelas se contextualizan en dramas de corrupción o discriminación con tintes de comedia

Sin embargo, Dávila (citada en Medina \& Barrón, 2010) menciona que entre los años ochenta y noventa, las historias presentadas en las telenovelas latinoamericanas cambian ante el interés de ser más universales que locales, y es que para Waisbord en un entorno globalizado habría que generar una identificación más universal para que el producto televisivo se comercializara de modo eficaz (citado en Medina \& Barrón, 2010).

Casas (2005) destaca el caso de las telenovelas mexicanas, las cuales han reflejado la cultura tradicional en el sentido religioso y en un nacionalismo exacerbado (citada en Medina \& Barrón, 2010); no obstante, ante una nortea- 
mericanización cultural, readaptó sus telenovelas y las convirtió en productos globalizados con relación a sus contenidos y enfoques. Sus dramas reflejaron las experiencias y problemáticas sociales de la modernidad, relacionada principalmente con la crisis de las familias, la violencia y los estereotipos de género. En cambio, para Medina \& Barrón (2010), las telenovelas mexicanas aún guardan esa esencia melodramática, conservadora y tradicionalista. Si bien se ha buscado matizar con historias apegadas a la realidad, aún sostienen los mismos dramas: relaciones de amor complejas y el culto a la pobreza.

A continuación, proponemos una clasificación de los tipos de telenovelas. En México, de acuerdo con su temática se pueden dividir en los siguientes grupos:

- Telenovelas femme fatale: centradas en mujeres bellas y ambiciosas que pueden resultar problemáticas para sus compañeros masculinos. Dentro de este grupo se podrían mencionar "Senda prohibida" (1957) y "Teresa" (1959).

- Telenovelas históricas: fundadas en la idea de recuperar relatos que han marcado la idiosincrasia local, como ejemplos, se pueden mencionar "Maximiliano y Carlota" (1965), que presentaba al emperador extranjero (como un hombre bello y heroico) y a Benito Juárez como un indígena escapando de la persecución y como un villano. Otro ejemplo relevante es "La tierra" (1974), que abordó la guerra cristera.

- Telenovelas de corte religioso: dirigida a una comunidad profundamente creyente como la de México. De este tipo se pueden citar "Fray escoba" (1973) o "Mundo de juguete" (1974-1977).

- Telenovelas hipersexualizadas: que presentan mujeres protagonistas muy alejadas de las historias rosas, como "La reina del sur" o "El señor de los cielos", que igual manejan temas de violencia y proponen una imagen de mujeres bellas e indomables.

- Telenovelas educativas o entretenimiento educativo: en "Simplemente María" (1970) se personifica una campesina que llega a la ciudad y se convierte en una exitosa diseñadora de moda a pesar de ser madre soltera. Otro ejemplo es "Ven conmigo" (1976) que refirió el tema de la educación adulta. Se enfatiza en el efecto que causó esta telenovela en México. Según García \& García, (2015), el analfabetismo alcanzaba a la mitad de la clase trabajadora. Finalizada la telenovela, ascendió a 300,000 la inscripción a escuelas de educación para adultos, un día después de la emisión del último capítulo. 
Las telenovelas colombianas se agrupan de la siguiente manera:

- Telenovelas de venganza: como el caso de "La viuda de blanco" (1996) o "Lola calamidades" (1987), en el que se presenta a la mujer como un formidable y maquiavélico enemigo, pero siempre ayudada por un hombre.

- Telenovelas costumbristas y literarias: como "El gallo de oro" (1982), "La vorágine" (1990) o "Café con aroma de mujer" (1995), que muestran las costumbres del país.

- Telenovelas místicas: basadas en creencias sobrenaturales, como "Luzbel está de visita" (2001) o "En cuerpo ajeno" (2010).

- Telenovelas históricas: que forman una parte importante de la identidad nacional, tales como "Los pecados de Inés de Hinojosa" (1988) y "La Pola" (2011).

- Telenovelas musicales: como "Perro amor" (1998) o "La reina del flow" (2018).

- Telenovela negra: género que aparece iniciando el siglo XXI, que abordan historias basadas en operaciones detectivescas o de actividades delictivas: "La saga, negocio de familia" (2004) y la comedia "Brujeres" (2000).

- Telenovelas educativas: destacan "Todos quieren con Marilyn" (2004) y "Francisco el matemático" (1999).

\section{Entretenimiento educativo (EE)}

El uso de esta categoría, como una estrategia de comunicación, crece significativamente. Este concepto se concentra en problemas de salud, adicciones, campañas de vacunación, reproducción familiar y (desde los últimos 15 años) en prevención de VIH-SIDA. Asimismo, se ocupa de informar a ciertos sectores de la población sobre problemas ambientales o resolución de conflictos. Los objetivos del EE son promover el cambio individual para sustentar un cambio social, así como articular la participación y el empoderamiento social de las minorías marginadas. El punto central es que esta estrategia se aplique cada vez más como una herramienta de los medios de comunicación (Tufte, 2005).

Igartua (2005) considera el EE como un modelo eficiente para estimular el 
aprendizaje. La fórmula que propone es integrar contenido educativo en productos destinados al entretenimiento, tales como telenovelas, series, programas de radio, videos musicales, caricaturas, programas infantiles, juegos y videos de entretenimiento, canciones, entre otros. La autora cree que, a través de la representación de una problemática y una recomendación de solución, será posible estimular un cambio de actitud individual y esto conllevaría a una transformación social, obviamente, no a corto plazo, ya que se trata de un aprendizaje a través de la repetición. Por su parte, Tufte (2005) lo define como el uso del entretenimiento a través de un medio comunicativo, que utiliza un diseño práctico diseñado estratégicamente para comunicar sobre problemas y propósitos que pueden variar e incidir social o individualmente.

A partir de la propuesta metodológica de Miguel Sabido \& Rubén Jara (1989), en la que se incluye el EE como una estrategia para crear programas utilizando categorías teóricas y problemáticas sociales, con esta estrategia se desarrollaron una diversidad de dramas en los medios de comunicación sobre las realidades que las personas enfrentan a diario. El objetivo principal de esta metodología es comunicar a nivel emocional y cognitivo, y con ello favorecer el aprendizaje social. El principio fundamental de esta metodología es que la educación no tiene que ser aburrida. Sabido originalmente llamó a su enfoque "entertainment with proven social benefit" (Barker, 2011, p. 4).

El éxito de la metodología de Sabido \& Jara (1989) depende de dos factores claves: a) uso del formato de drama en serie y b) rigurosa aplicación de las teorías subyacentes a la metodología (teoría dramática, teoría de la comunicación, teoría del aprendizaje social). Mientras que la mayoría de los programas de educación con EE están dedicados a enviar mensajes, la metodología de Sabido \& Jara (1989) usa personajes como modelos a seguir para demostrar el comportamiento deseado (Barker, 2011).

Los dramas seriales (que se transmiten por meses o incluso por años) constituyen un método eficaz de educación y entretenimiento que pueden influir en el cambio de comportamientos porque:

- Capturan la atención y las emociones de la audiencia en forma continua.

- La presencia constante permite que la audiencia empatice con los personajes, sus problemas y el medio en que se desenvuelven.

- El tiempo de transmisión de las series (años o meses) permite a los 
televidentes observar que los personajes padecen dudas y problemas como en la vida real. Perciben en cada capítulo cómo se generan cambios de comportamiento, de manera que pueden constituirse en fuente de inspiración para generar una transformación de actitudes.

- Cada capítulo puede organizarse a través de subtramas que introduzcan problemáticas de una manera lógica, creíble y con diferentes personajes.

- La repetición posibilita que se traten los problemas en forma profunda y desde distintos enfoques. (Barker, 2011, p. 5)

Al modelar el proceso de cambio gradualmente, los dramas en serie son menos propensos a provocar reacciones negativas por la audiencia que aquellos programas que intentan generar un cambio rápido. Idealmente, los dramas seriales (al estilo propuesto por Miguel Sabido) deberían continuar durante al menos 120-180 episodios (en el transcurso de dos o más años). Pueden presentar diferentes perspectivas y estimular preguntas y debates de la audiencia que conduzcan tanto al cambio de comportamiento individual o social. De todos los formatos para programas de educación de entretenimiento (que han sido adaptados a un drama serial y considerando que el acceso a la televisión es ilimitado) se demostrarían que estos dramas seriales son formatos efectivos para promover cambios a largo plazo (Barker, 2011).

Una experiencia exitosa fue la estrategia de Miguel Sabido, quien tomando la teoría sociocognitiva del aprendizaje social de Bandura (1973), realizó siete telenovelas de 1975 a 1982, inspirado en "Simplemente María" (1969-1971), melodrama que sentó las bases del entretenimiento educativo (Igartua, 2005). Una primera experiencia fue la telenovela "Ven conmigo" (1976), la cual (con un plan de producción y contenido "prosocial") impulsó a que un millón de iletrados se registraran en el Plan Nacional de Educación de Adultos. Con estos resultados, se elaboró un segundo modelo con una innovación: la de utilizar en su diseño la teoría del aprendizaje social de Bandura (1973). Así surgió “Acompáñame" (1977), que trata el tema de la planificación familiar y ligada al Plan Nacional. A la larga, esta telenovela se convirtió en una de las mayores motivaciones para que cerca de medio millón de mujeres mexicanas demandaran servicios de planificación familiar. Además, durante el tiempo en que la telenovela se transmitió, aumentaron las ventas de contraceptivos en México (Sabido \& Jara, 1989). 
Un tercer modelo de diseño de telenovela fue utilizado para producir "Vamos juntos" (1979). Esta teleserie se caracteriza por no haber defendido un valor único, sino una red de valores. En "Vamos juntos", el mensaje se basaba en la preocupación de las Naciones Unidas por los derechos de los niños (Sabido \& Jara, 1989). Un elemento básico del EE es el impacto de la metodología propuesta por Sabido. Morris (citada en Tufte, 2005) nos dice que "popularidad" no es lo mismo que "eficacia". Sherry (citado en Tufte, 2005). en una revisión que hizo de 20 telenovelas que utilizaron el EE, no encontró un cambio significativo en el aprendizaje, actitudes o conductas de la audiencia. Por lo tanto, se necesitan algunas aclaraciones para comprender las posibilidades y limitaciones de la estrategia del EE (Tufte, 2005), con el propósito de construir una herramienta que nos lleve al logro de los objetivos trazados.

En ese sentido, hay que definir varios puntos:

- Fines y objetivos que impulsan las estrategias de EE.

- Tipo de sociedad que se interviene.

- Alcance de los cambios que se buscan.

- Resultados que se buscan.

- Coordinación entre el género utilizado y la realidad social.

- Creativos que desarrollan la estrategia y la narrativa.

- Tiempos establecidos.

- Evaluación del impacto del producto con EE. (Tufte, 2005, p. 162)

La telenovela probó que no es sólo una forma de entretenimiento con éxito comercial, sino también un medio adecuado de proveer educación informal a la audiencia. Sobre la base de estas experiencias, se tuvo la idea de usar deliberadamente a las telenovelas para enviar mensajes prosociales. Para este propósito, se desarrolló un marco teórico interdisciplinario alimentado por las siguientes fuentes:

- Teoría dramática: basada principalmente en las ideas en que se analizan los efectos que producen en la audiencia las técnicas teatrales. Esta teoría trata a la telenovela como un melodrama y se fija en su estructura, el desarrollo del tono, anécdota, tema y personajes para obtener conocimientos sobre cómo esta configuración dramática puede influir en la audiencia.

- Teoría de la comunicación: propone un modelo que describe los ele- 
mentos que intervienen en un proceso de comunicación, que coloca a las telenovelas dentro de ese proceso, ayudando a describir las funciones y efectos producidos por cada uno de los elementos dentro del acto comunicativo.

- Teoría del aprendizaje social: explica como las telenovelas pueden tener éxito en lograr que el televidente, a través del proceso de identificación y de sufrir experiencias ajenas, imite el comportamiento de los personajes que promueven y defienden valores sociales.

Cabe entonces la siguiente interrogante: ¿cómo debería ser una propuesta de representación de la vejez, incluyendo la perspectiva de género y la metodología del EE en las telenovelas? A continuación, a través de la metodología aplicada, trataremos de responder esta pregunta:

\section{Metodología}

Tomando en cuenta la teoría del aprendizaje social expuesto por Sabido \& Jara (1989) se puede considerar lo siguiente:

La teoría propuesta por Bandura (1973) parte del concepto de la "imitación", apelando a las células espejo que todo ser humano tiene y que explica cómo las telenovelas generan aprendizaje, al presentar comportamientos modelo que los televidentes pueden imitar: la identificación con otros da forma a los pensamientos, sentimientos y acciones. De esta manera, un acontecimiento que provoca identificación, se define como la ocurrencia de similitudes entre el comportamiento modelo y el de la persona que representa el modelo a imitar.

Pero, se abre otra cuestión, ¿cómo se produce la identificación? y ¿por qué algunos modelos generan imitadores y otros no? Bandura (1973) afirma que los modelos no están confinados al entorno inmediato, ni tampoco se puede esperar que los arquetipos presentados en la tele sean aceptados per se, sino que la imitación está diseñada para encuadrar dentro de una variedad de actos que provengan ya sea de experiencias directas o de un contexto simbólico afín con su modelo de vida.

Lo que se hace en la televisión (con sentido educativo) es reforzar el miedo a las consecuencias sociales asociadas al comportamiento indeseado. Este tipo 
de acción es básica para que ocurran, se retengan y se practiquen los nuevos comportamientos. La reproducción de un modelo nuevo trae sus propias consecuencias y esas consecuencias determinan que este se continúe reproduciendo en el futuro. En ese sentido, Sabido \& Jara (1989) establecen la necesidad de identificar a un comunicador que definirá el valor a promoverse. Este valor tendrá que ser recodificado en actitudes arquetípicas, las que se convertirán en el mensaje de la telenovela. Estas actitudes se traspasan a estereotipos, esto es, los personajes que servirán (o no) como modelos de identificación a los televidentes.

La situación que refleja la anécdota de la telenovela modificará o reforzará sus actitudes hacia los valores sociales transmitidos y, más tarde, realizará comportamientos en consonancia con la infraestructura que provee el comunicador. Una vez que el valor ha sido practicado individualmente, comenzará un proceso de diseminación interpersonal que llevará a la modificación o refuerzo de otras personas y, eventualmente, de la sociedad en general (Sabido \& Jara, 1989).

Este proceso comprende tres niveles que, aunque implícitos, deben ser verbalizados dentro del drama para que sean considerados no solamente en la configuración de la telenovela sino, también, en cualquier tipo de comunicación. Los niveles presentes en el refuerzo de valores morales son: motivación hacia los valores, conocimiento del conjunto de valores y representación de los comportamientos relacionados con los valores (Sabido \& Jara, 1989).

Dentro de este proceso, los medios de comunicación colectiva deben ser manejados de formas distintas:

Deben usarse para sensibilizar a la audiencia, promover identificación, motivar cuestionamientos, presentar modelos de comportamientos, alentar expectativas personales y familiares y sancionar los valores. Todo esto tendrá lugar a través de la transmisión de mensajes con contenido emocional

El medio puede utilizarse para difundir información acerca del valor o conjunto de valores y sobre las instituciones encargadas de garantizar los modos de poner en práctica los comportamientos deseados, con la intención de que la audiencia adopte el comportamiento en dos niveles, el personal y el institucional. (Sabido \& Jara, 1989) 
A continuación, se ofrece una explicación del proceso metodológico para la creación de la propuesta orientada a la vejez con perspectiva de género, en la que se incluye la metodología de Sabido. Iniciamos con el estudio de cuatro telenovelas de alto rating en México y Colombia para reconocer la inclusión de vejez y perspectiva de género. En este sentido, se trabajó desde el análisis crítico del discurso con el fin de reconocer los significados simbólicos de los mensajes. De acuerdo con Van Dijk (2002), este tipo de análisis busca identificar los recursos lingüísticos (y códigos visuales) que manifiestan la posición de un grupo social con respecto a otro. En este caso, se reflexiona sobre la forma en qué se manifiesta y se potencia la visión de las productoras de telenovelas, sobre las personas mayores.

Los medios funcionan como una interfaz "entre discurso y sociedad uno puede llamarla 'representativa' o 'indexical', en el sentido de que las estructuras del discurso hablan sobre, denotan o representan partes de la sociedad" (Van Dijk, 2002). Para interrogar a las telenovelas y reconocer la forma en que trabaja esa "interfaz", se realizó un cuestionario que permitió realizar una visualización del fenómeno social estudiado y las dimensiones en que representan a los adultos mayores.

Los criterios de observación de la muestra fueron los siguientes:

- ¿Qué hacen los adultos mayores?, ¿cuál es su ocupación?

- ¿Cómo representan las historias a las mujeres y a los hombres?

- ¿Qué relación tienen con él o la protagonista?

- ¿Qué estereotipos se manejan con respecto al adulto mayor?

- ¿Cómo se presenta la estigmatización y segregación del adulto mayor o de su idea?

Las características que se buscaron para seleccionar las telenovelas fueron: $a$ ) que estuvieran dentro de las más vistas tanto en Colombia como en México y b) que tuvieran dentro de su grupo artístico a más de dos personas mayores dentro de los roles principales o cercanos a los protagonistas. ${ }^{1}$

1. Se tuvo que hacer un largo rastreo para conseguir telenovelas con estas características, fue necesario regresar a través de la última década hasta completar una muestra de cuatro telenovelas que cumplieran con los requisitos. 
Las telenovelas seleccionadas fueron dos mexicanas: "La patrona" (emitida en 2013) y "Victoria" (emitida en 2008), y dos colombianas: "Chepe Fortuna" (emitida en 2010) y "Pasión de gavilanes" (emitida en 2003).

El tipo de muestra fue del tipo intencional que consiste en un muestreo elegido a juicio del investigador. Con el objeto de lograr una muestra significativa, la unidad de análisis estuvo representada por 60 adultos mayores hombres y mujeres, de 60 años en adelante, provenientes del departamento del Quindío (Colombia) y 60 adultos mayores de Ciudad Juárez (México) para un total de 120 entrevistados.

\section{Discusión}

Aparte de ser uno de los fenómenos mediáticos del siglo XX y XXI predilectos en Latinoamérica, las telenovelas son también una representación de la identidad. Al exponer los rostros, los espacios y los conflictos propios de la gente trabajadora (alejada de los problemas políticos o pugnas de poder que atraviesan los países del subcontinente), garantizan una integración entre medio y televidente.

Dos de los conflictos que se reflejan en las telenovelas (y que quisimos explorar por parecernos pertinentes) son la relación entre la telenovela con la vejez y el género. A la luz de los últimos datos demográficos, es decir, de que la mayoría de los países latinoamericanos están envejeciendo pasando de un $9 \%$ a un $11 \%$ (INEGI, 2015), aunado al hecho de que la población mayor que más crece es la femenina, puesto que la tasa de sobrevivencia de las mujeres es más alta. (DANE, 2018). El siguiente problema es el de la violencia de género que se reconoce como endémica en Latinoamérica.

En gran medida, se atribuye a que la cultura patriarcal tan arraigada rige prácticamente todas las costumbres y prácticas de la vida diaria, las cuales han relegado y limitado los derechos y libertades de las mujeres. Esta cultura naturaliza la violencia contra la mujer, produce estereotipos, perpetua y reproduce la discriminación. En Latinoamérica, son las que más sufren los efectos de los bajos niveles de ingreso y la desigualdad. (Moreno \& Pardo, 2018) 
Por estas razones esbozadas por Moreno \& Pardo (2018), es que decidimos investigar en cuatro telenovelas, los estereotipos de género y vejez representados. La mirada que las telenovelas presentan sobre las personas mayores y la reproducción de estereotipos no solo por su edad, sino por su género realizados por las empresas productoras, delata la madurez o inmadurez, las faltas o bondades, con que las personas estén aceptando a este grupo poblacional y desde ahí se hizo posible esbozar un producto mediático que trate de contrarrestar los dañinos efectos de la difusión de estereotipos y la discriminación.

\subsection{Análisis de la vejez representada en las telenovelas elegidas}

El análisis de contenido de las telenovelas se realiza desde tres niveles: a) uno superficial, que señala la intención de su anécdota o argumento, b) uno profundo, que se adentra en las formas de presencia del adulto mayor dentro de su construcción y c) un nivel emocional, que estudia la estructura emocional que se adhiere a la trama.

"Victoria", producida por Telemundo en el 2007, es una adaptación de la telenovela mexicana "Mirada de mujer", transmitida en 1997. Relata la vida de una mujer de 50 años, madre de tres hijos, perteneciente a una clase social alta. Después de 25 años de matrimonio, Victoria se enfrenta a un divorcio cuando descubre la infidelidad de su esposo con una mujer joven. Sin embargo, su vida da un vuelco cuando se enamora de un hombre 10 años menor que ella e inician un romance. "La patrona" (2013), telenovela producida por Argos Televisión para Telemundo, es una adaptación de la telenovela venezolana "La dueña". Relata la vida de dos mujeres muy diferentes que deben enfrentarse entre ellas para alcanzar sus metas. Una es Gabriela Suárez, de profesión minera y madre soltera; la otra es Antonia Guerra apodada "la patrona", dueña de la mina, viuda en varias ocasiones y de la que se presume fue la causante de la muerte de sus esposos. Además, es madre de un hijo abusador de mujeres al que ella protegerá a cualquier costo.

"Pasión de gavilanes" (2003), telenovela escrita por Julio Jiménez, es un remake de la telenovela "Las aguas mansas" (1994), en un intento por internacionalizar las producciones colombianas. Cuenta la historia de los tres hermanos Reyes quienes (para vengar la muerte de su hermana) deciden hacerse pasar por trabajadores de la familia Elizondo, comprendida por los esposos, 
el abuelo y las tres hijas que finalmente harán flaquear los deseos de venganza de los hermanos. Y la telenovela "Chepe Fortuna" (2010) emitida por el canal $R C N$, una historia de tipo costumbrista ubicada en la zona de la costa Caribe, que narra la historia del líder social José "Chepe" Fortuna y Niña Cabrales, una joven mujer de familia rica y con el interés de ayudar a las comunidades menos favorecidas. Cuando se encuentran parece que están destinados uno al otro hasta que la familia Cabrales decide hacer una ampliación de la naviera que pondrá a Niña en medio de Chepe, la comunidad y de su propia familia.

Las cuatro telenovelas gozaron, en su momento, de altos rating de sintonía y se ganaron premios del público por las excelentes actuaciones de los actores que representaron a los personajes principales. Pero lo que aquí nos convoca son los personajes que representan a hombres y mujeres mayores.

\subsubsection{Telenovela "Victoria"}

Las tres mujeres protagonistas (Victoria Santisteban de Mendoza, Helena de Cárdena y Camila Matiz) tienen entre 50 y 60 años y se las considera "personas mayores" dentro de la historia. ${ }^{2}$ En esta telenovela se evidencia una realidad de la mujer: después de los 50 e incluso a los 40 años, las envuelve un prejuicio social que las saca de los círculos de la contienda amorosa. En los diferentes capítulos pareciera que al alejarse de la edad fértil (o mejor dicho, de la juventud), las mujeres pierden su atractivo y en lugar de atraer, repelen a los hombres. No obstante, también es la etapa más productiva en términos intelectuales y monetarios: es un momento en que la mujer ha alcanzado todo su potencial y está disfrutando de los frutos de lo que ha sembrado a lo largo de su vida.

Cada una de las mujeres "mayores" de la telenovela representa un tipo de mujer madura. Camila Matiz es la mujer que se niega a envejecer, depende de la mirada de los otros para validarse a sí misma y sólo siente seguridad cuando encuentra un nuevo enamorado. Lo que ella muestra es un aspecto de

2. Pese a que no están dentro del rango que la Organización Mundial de la Salud (OMS) determinada para identificar a este grupo. De esta forma, se estaría demostrando que los medios de comunicación generan una idealización de la juventud, siguiéndose la idea de Bandura (1973), en cuanto a que (ante la repetición del esquema) podrían influir en comportamientos discriminatorios sobre este grupo poblacional. 
las mujeres que han sido víctimas de los estereotipos sociales de "eterna belleza" que presionan a las mujeres. El bombardeo mediático y social, en este sentido, es tan alto que no da espacio para que las personas piensen en que es imposible evadir la edad o alcanzar esos estándares.

Victoria, la protagonista, representa a la mujer que aceptó el destino social y biológico que la sociedad les impone a todas las mujeres, es decir, casarse antes de los 30 y tener hijos antes de los 35 . Solo que eso no es un destino, sino una imposición a la que muchas mujeres se acostumbran. Por eso, cuando el esposo la abandona, ella despierta a la "vida real": a una vida sin un destino marcado y tendrá que elegir entre volverse a enamorar o quedarse sola viviendo para sí misma. Victoria es una representación del rompimiento del estereotipo de la mujer que solo vive para los demás. Aunque le cueste, ella aprenderá que es una persona que vale y no necesita de los otros para considerarse un ser valioso.

Cuando Victoria decide salir con un hombre menor debe enfrentarse a la crítica social que surge a su alrededor: familia y amigos se dividen y toman partido frente a su decisión. La cuestionan desde el aspecto social, moral e incluso mental, pues muchos creen que se ha vuelto "loca". Es una manifestación de la discriminación que hay hacia la mujer en cuanto a su acercamiento al amor y al sexo. Mientras que el hombre goza de total libertad (puede salir con todas las mujeres que quiera y entre más jóvenes mejor), a las mujeres se les debe restringir hasta que prácticamente se les anule como seres físicos y espirituales. ${ }^{3}$

Entretanto, Helena de Cárdenas representa el "ideal" de mujer madura: casada, con un matrimonio estable, ama de casa, con un hijo ya entrando en la adultez, nunca levanta la voz a su esposo y (para completar el cuadro) es la consejera de sus amigas. Este personaje se puede decir que es un "frasco vacío", alguien incapaz de producir una sorpresa, es el conjunto de estereotipos que marcan a la mujer como un ser marginal, una persona que sirve como escalón de apoyo para que su esposo e hijo florezcan mientras ella los mira.

3. Al respecto, Freixas afirma que "el aumento espectacular de la esperanza de vida en el siglo XX ha otorgado un espacio anteriormente jamás imaginado a la erótica en la madurez" (citada en Carpallo, 2018). Por lo que ya empieza a reconocerse la existencia de los romances entre mujeres mayores con hombres menores, en algunos años se romperá el tabú y se convertirá en algo cotidiano. 
De acuerdo con Tribuna feminista (2016), se encontró que el 70\% de la publicidad marroquí muestran a la mujer como dependiente del varón, frente al $15 \%$ en Cataluña y el $7 \%$ en Andalucía, mientras que el 100\% de los anuncios muestran a los hombres como detentadores del poder. Esto es una muestra de cómo los medios ayudan a prosperar los preconceptos negativos que flotan en el imaginario social. Los estereotipos de mujer madura (representados en Victoria) revelan los imaginarios sociales alrededor de las adultas mayores en Latinoamérica: que serían (en primera instancia) vanidosas, preocupadas por su apariencia, que han cumplido con su "deber social" al casarse y tener hijos pero atentan contra lo socialmente aceptable al ocuparse de otros asuntos como enamorarse de alguien menor.

\subsubsection{Telenovela "La patrona"}

Se pueden ver tres personajes: Antonia Guerra, Gabriela Suárez y Tomás Suárez. Este último, hombre mayor de escasos recursos, es representado como un padre bondadoso y honrado, pero sin carácter, dando a entender que las personas mayores que carecen de recursos económicos se someten a los demás y no tienen capacidad de decisión, siendo su única labor la de ser apoyo emocional de sus hijos. Este tipo de personaje lo analizaremos más a fondo en la telenovela "Pasión de gavilanes".

Gabriela Suárez sufre el estigma de la pobreza y es madre soltera: dos condiciones que la sentencian a ser maltratada y que, de algún modo, la obligan a volverse más fuerte que los demás para enfrentarse a la sociedad y solucionar sus problemas. Pasa del estereotipo de "niña buena" (que nunca responde a nada y se deja maltratar) a "mujer salvaje", que se la pasa gritando y poniéndose en contra de todo el mundo. También se aprecia el hecho que (por ser mujer) recibe menos salario que sus colegas masculinos, aunque cumplan con las mismas tareas.

Aunque la idea de una madre soltera no afecta para nada (sobre todo en pleno siglo XXI) es claro que aún existen culturas en donde esto es un estigma, especialmente dentro de los grupos sociales menos favorecidos, en los que todavía persisten ideales conservadores muy arraigados. El matrimonio aún está vinculado al ideal de "respetabilidad" de una mujer, unificando en un solo estereotipo el destino "biológico" (la obligación de ser madres o padres) 
con el destino "social" (la necesidad, sobre todo para las mujeres, de estar casadas).

Es otra manifestación de cómo la sociedad sigue condicionando el desempeño sexual femenino, como si fuera algo del colectivo y no su decisión personal. El concepto patriarcal anuncia que una mujer no tiene derecho a ser madre cuando ella quiera, sino cuando está casada, esto con el fin de demostrarle a la comunidad que se relaciona sexualmente con un solo hombre.

Las madres solteras pueden ser juzgadas por privar a sus hijos de la figura paterna. Pero algunos estudios han demostrado que el niño necesita adultos con los qué establecer lazos comunicativos para tener un desarrollo armonioso y no necesariamente un padre. De hecho, es más perjudicial para un niño contar con la figura de un padre distanciado y que nunca está cuando lo necesita. (Supermujer, 2015)

Como se puede apreciar en la anterior cita, las mujeres no necesitan de un hombre para educar a sus hijos (igual se aplicaría a padres solteros). Ser madre o padre soltero es cada vez más común y no es motivo de vergüenza. Según datos de la Cepal (citado en Unisabana, 2014), América Latina solo está un escaño arriba del África subsahariana en cuanto a "madresolterismo" y en maternidad adolescente. Cuesta creerlo, pero Colombia es el país con más madres solteras en el mundo, $62 \%$ del total, frente a un $27,8 \%$ de mexicanas (Unisabana, 2014), lo que también demuestra la aceptación social que hay en Colombia en cuanto a la mujer como "cabeza de hogar" y el concepto conservador que aún se maneja en México.

Siguiendo con esta telenovela, tenemos a Gabriela Suárez, quien es sin lugar a duda una manifestación de lo poco que se ha avanzado socialmente en materia de derechos sexuales y reproductivos en América Latina, pero también en materia de igualdad de derechos laborales. Antonia Guerra representa a la mujer mayor de alta posición social. Al ser rica y poderosa (por descarte) se convierte en una "arpía" quien, por encima de cualquier consideración, va a alcanzar sus deseos. Si es mayor, viuda y rica tendrá en su conciencia la muerte de sus anteriores esposos. Cumple el preconcepto de "viuda negra", que es otro capricho social para discriminar a la mujer, pues de acuerdo a este, no existe la mínima posibilidad de que una mujer haya levantado una fortuna por su propio esfuerzo. 
De esta manera se aprecia cómo el sistema patriarcal define "lo humano" desde "lo masculino", desde sus intereses y sus miradas. Ese sentido, la mujer solo es un objeto de placer sexual, por lo tanto, su posición dentro del ámbito del poder procede de ahí. "Ello demuestra claramente que las instituciones políticas y sociales más elementales no se hallan basadas en la riqueza o en el rango, sino en el sexo. El rasgo más característico y primordial de nuestra cultura radica en su enraizamiento patriarcal" (Amorós, 2005, p. 15).

El desarrollo que se le da al personaje de Antonia Guerra, en una telenovela que se supone es precisamente hecha para ser vistas por mujeres (especialmente amas de casa, que tienen la televisión como un medio para alimentar su mente) dice mucho del concepto patriarcal que encierra este personaje y se puede resumir en la siguiente cita:

Cuando las mujeres pretenden elevar su estatus en el registro político, siempre se les puede recordar que su verdadero estatus, en última instancia, lo determina la jerarquía sexual y sus jerarcas pueden decidir, si lo consideran oportuno, "reducida al estatus de simple hembra". (Amorós, 2005, p. 16)

La representación de la mujer poderosa queda signada por sus antivalores más femeninos, es decir, se trata de mujeres extremadamente sexuales e irascibles. Cuando son madres son hiperprotectoras, pero sobre todo son mujeres sin lazos masculinos (porque Dios nos libre de una mujer que no tenga un hombre al lado que la domine) y que alcanzan su poder gracias a intercambios sexuales.

\subsubsection{Telenovela "Pasión de gavilanes"}

En esta telenovela se enriquece un poco la presencia de los adultos mayores. Vale la pena resaltar que es la primera de las analizadas donde se muestran diversos tipos de relación entre personas mayores y no mayores. El doctor Leónidas Coronado (un hombre casado al que poco le importa su mujer Conchita) se enamora de la señora Melissa de Santos: una mujer que ha viajado por el mundo y ha vivido todo tipo de experiencias.

El otro prototipo es de la señora Gabriela Acevedo de Elizondo: una mujer de muy alta alcurnia a la que le importa el "qué dirán". No puede evitar que el 
abandono emocional (a la que su marido la tiene arrinconada) la lleve a sentir atracción por su interesado y mujeriego yerno, Fernando Escandón.

Como es normal en las telenovelas, al no ser las parejas centrales, se trata de amores fallidos o destinados a ser el alivio cómico, pues el triángulo Leónidas-Conchita-Melissa genera las escenas más graciosas en toda la historia, las cuales aparecen justo en los momentos en que hay más tensión dramática. En cambio, la relación entre Gabriela y Fernando nunca se concreta: se limita a algunos escarceos que él le permite a la mujer para tenerla interesada, pero que jamás dejará que lleguen más allá debido a que la considera "fea" por el hecho de ser mayor, no porque sea la mamá de su propia esposa, algo que a él le tiene sin cuidado.

Esta mirada del amor entre mayores (como algo gracioso o digno de lástima) sólo expresa la cualidad atribuida de ser personas desactualizadas e incapacitadas, además de presentarlos como sujetos manipulables. Contemplar e interpretar de esa forma el amor entre los mayores implica desestimar su capacidad de amar e infravalora sus necesidades tanto físicas como emocionales, dándole a entender al público que al llegar a esas edades no tienen derecho a tener expresiones de amor y el castigo será el ser expuestos a la ridiculización o a la decepción.

Asimismo, aparece la representación estereotipada de las personas mayores como personas "enfermas" y "débiles". Los personajes Calixto Uribe y Martín Acevedo representan a dos hombres bastante mayores, adinerados, que terminaron postrados en sillas de ruedas al cuidado de sus hijos. El primero es un hombre eminentemente bueno que padece alzhéimer y el segundo es un coronel retirado del ejército al que todavía le sobran bríos para enfrentarse a las malas decisiones de su hija y a las maldades de su yerno.

Se puede decir que esta representación del adulto mayor enfermo es coherente con la marginación social y familiar que los personajes sufren, pues ese es uno de los graves problemas que enfrentan los mayores cuando son sólo vistos como "cargas". Aunque la percepción que se tiene de ellos es suavizada cuando tienen dinero.

Las actitudes de los miembros de una comunidad hacia los mayores se encuentran relacionadas en forma estrecha con la imagen que so- 
cialmente se mantiene de ellos y, ésta se relaciona a su vez, con la posición social que las personas mayores disfrutan en dicha comunidad. (Fajardo \& Olivares, 2008)

La sociedad moderna ostenta valores centrados en la capacidad de las personas para acumular bienes y en unos cánones de belleza imposibles, catalogando a las personas en función de su apariencia física y la extensión de su billetera. Ambas condiciones ("belleza" y "dinero") están signadas por el ideal de productividad: la vejez no sólo no es bella, sino que no es productiva y ya que la belleza indica "juventud" y "agilidad", son dos atributos que no tendrían los ancianos. Entonces se concluye que en "Pasión de gavilanes", las personas mayores (como ya no trabajan y no han acumulado dinero para su vejez) están condenados a la soledad o a convertirse en una molestia dentro de sus familias, un estigma que muestra la cruda realidad de los mayores en nuestros países.

\subsubsection{Telenovela "Chepe Fortuna"}

En esta telenovela, los adultos mayores representados y de mayor protagonismo son Úrsula Cabrales, una mujer "mandona" que define al mundo por sus apellidos y Jeremías Cabrales, el "viejito bonachón y sabio", quien después de haber hecho su fortuna se dedica a disfrutar la vida. También aparece una mujer madura (Malvina), una viuda amargada: es la típica mujer que actúa por interés, pues en lo único que piensa es en el dinero que le van a heredar sus suegros cuando mueran.

Estos tres personajes son la viva representación de la tradición, del estatuto del pater familia y de los estereotipos fundamentales de adulto mayor: "hombre" = "sabio", "mujer" = "insegura". Este tipo de personas son los adultos mayores que lideran el núcleo familiar y de los cuales depende el buen estado de las relaciones entre los miembros del clan. No obstante, al hombre lo muestran como alguien tranquilo, afable y esencialmente bueno, porque goza de la tranquilidad que le da una vida de trabajo en la que se ha ganado a pulso todo lo que tiene. Por lo tanto, es indiscutiblemente el dueño de la fortuna y de la línea familiar. Mientras que las mujeres nunca realizaron labor económica fuera de casa. Eso quiere decir que la fortuna no les pertenece, sólo el apellido y la imagen de la familia que ellas sostienen a capa y espada. 
El caso de Malvina es diferente. Ella se casó por el interés que le despertó el dinero de la familia Cabrales, pero al enviudar quedó sola con una hija y pensó que heredaría el dinero que le correspondía a su esposo. Sin embargo, la herencia le fue negada, quedando supeditada a los mandatos de Úrsula y Jeremías. Esta actitud de subordinación corresponde a lo que Amorós (2005) denomina una "colonización interior", que se traduce no sólo en "lucha de clases", sino en la necesidad de pertenencia que para muchas mujeres queda vinculada a la dependencia del rol que la sociedad les ha asignado.

La manera inmediata como se expresa la subordinación de las mujeres es la carencia de prestigio tanto del genérico como de las actividades y espacios relacionados con él, así como por la falta de poder (aunque no de resistencia), entendido como la inhabilitación simbólica para autogobernarse (con todo lo que esto implica) que se atribuye a todas las personas identificadas como parte del colectivo mujeres. (Serret, 1998, p. 145)

No es sólo que Malvina sea una mujer interesada, sino que simbólicamente fue despojada de su identidad al convertirse primero en "la mujer de" y luego en "la viuda de". Después la convencieron de que su hija tenía más posibilidades de heredar (como miembro de la familia de su esposo muerto) para culminar con el despojo que le hicieron de la herencia, llevándola a vivir con sus suegros para poder subsistir. Aunque la personalidad de la mujer no fuera la más agradable, no cabe duda que la orillaron hasta no dejarle más opción que ser virtualmente la "esclava” de los Cabrales.

\section{2. ¿Cómo son y cómo deberían ser las telenovelas a partir de que se integre una metodología de EE con relación a los temas de vejez y pers- pectiva de género?}

De manera general se observa en estas telenovelas que no existe una perspectiva de género y mucho menos de envejecimiento activo. No se trabajó con los presupuestos del EE o, al menos, una intención de apoyo social. Frente a estos hallazgos, se pasó al segundo objetivo de esta investigación, que consistió en 10 talleres de 2 horas con mujeres mayores, con las que se hizo un ejercicio creativo de cómo los adultos mayores debían ser representados. De estos surgieron las siguientes observaciones: 
- Quieren ser reconocidos como seres con potencial y derechos, el derecho a trabajar, a amar, ser amados y a tener una vida sexual activa.

- No quieren que se reduzca su imagen a la de personas enfermas o sin metas, cuando ellos son mucho más.

- Dado que ahora alcanzan la vejez con un mayor nivel de educación, se debe reconocer que llegan sin las cargas de ser unos "viejos inútiles". Al contrario, se sienten personas con muchos deseos de hacer y de aprender más, solo que no quieren seguir cumpliendo horarios, ni con obligaciones que ocupen todo su tiempo.

- Aman la independencia que les da tener una jubilación y el ser capaces de decidir cómo invierten su tiempo y dinero

- Disfrutan la libertad que les da la experiencia y el opinar sin supeditarse a ser juzgados por sus pensamientos.

- Las mujeres quieren que no se les califique desde su aspecto, ellas siguen siendo bellas, pero es una belleza diferente, más libre.

- Las mujeres también piden que se les tenga en cuenta su capacidad laboral, la cual no disminuye por tener más años.

- Tampoco quieren que se las reduzca a la posición social de su marido o su familia, ellas como seres autónomos tienen su propio estatus.

- Reconocen que algo que les gustaría ver en las telenovelas, además de que los adultos mayores sean tratados como seres productivos, activos y autónomos, es que entre todos ellos hay una vinculación con el recuerdo. La nostalgia no es el punto central, sino la de la reunión que reaviva viejas experiencias.

Con todos estos conceptos, el grupo creativo de adultas mayores (que aceptó ayudar en la investigación) elaboró una miniserie web, en la que trataron de concentrarse en los elementos mencionados. A continuación, se relata la historia general de la trama.

El argumento inicia con una mujer (Josefina) que le pide a su hija de 50 años, desempleada por culpa de su edad (discriminación por edad), que realice una reunión de sus antiguos compañeros de escuela (valoración del pasado). Así conocemos a Emilio (de 80 años que ha sido abandonado por sus hijos), a Esperanza, una famosa diseñadora que luego de la jubilación le tocó quedarse a cuidar a sus nietos (maltrato 
al adulto mayor), a Josefina que solo quiere disfrutar la vida, tener novios y pasear y a Rosa Helena, quien a sus 76 años quiere emprender un nuevo negocio, pero no le dan crédito por su edad (envejecimiento activo, productividad del adulto mayor y discriminación por edad). Entre todos ellos se organizarán un evento social para cumplir los sueños de cada uno y así demostrar que no están al final de la vida, sino al inicio de una nueva.

Aplicando la metodología de Sabido \& Jara (1989), a través de los factores claves: a) uso del formato de drama en serie, y b) rigurosa aplicación de las teorías subyacentes a la metodología (teoría dramática, teoría de la comunicación, teoría del aprendizaje social). Se eligió como formato dramático la "comedia suave", agrupada dentro de una miniserie de varios capítulos, que apoyan la idea de Bandura (1973), en cuanto a la repetición de las ideas para poder generar el aprendizaje y el cambio de valores, que en este caso se relaciona con la perspectiva de género y el respeto a las personas mayores.

Se escogió la serie como formato dramático, porque permite una identificación con los adultos mayores representados y sus situaciones, capturando las emociones del televidente a través de las experiencias resaltadas en los personajes. Este formato (dado que permite la repetición y la continuidad) motiva a que los espectadores reconozcan el problema y las posibilidades de cambio.

\section{Conclusiones}

En las cuatro telenovelas analizadas se destaca el maltrato al adulto mayor y la naturalización de estereotipos de discriminación de género sobre la mujer, reduciéndola a su destino biológico y a la universalización de la idea de humano definida por lo masculino. Esta visualización genera actitudes de rechazo y de desmoralización de los espectadores al momento en que enfrentan su propia vejez o la de otros.

Se puede decir que cada telenovela se enfoca en un estereotipo principal, siendo las telenovelas "La patrona" y "Victoria" las que más vulneran a la mujer al mostrarla dentro de esquemas negativos. La telenovela "Victoria" recrea una importante etapa de la vida de la mujer, entre los 50 y 60 años, 
que es cuando está entrando en la menopausia, finalizando su etapa laboral y cuando empiezan a experimentar la etapa del "nido vacío". Como punto positivo, se puede afirmar que es una recreación que se acerca bastante a la realidad, pero ayuda a considerar la idea del envejecimiento activo, es decir, a una acción que muestra la autodeterminación y empoderamiento, cuando muestra a la mujer como un ser capaz de volver a vivir el amor, superando los tabús de la edad.

En las telenovelas "Pasión de gavilanes" y "Chepe fortuna" se trabaja (en el caso de los hombres) la imagen negativa del adulto mayor, mostrándolo débil, enfermo y dependiente, centrándose en su respaldo económico como fuente de su seguridad física y psicológica. Mientras que los sujetos femeninos son representados como seres amargados y avaros que lograron su fortuna a través del matrimonio, por lo que dependen de la supervivencia de su marido para disfrutar de su riqueza, reforzando así la idea de que las mujeres son seres dependientes, inseguros y restringidos al espacio doméstico.

La propuesta general de las participantes del taller mostró una necesidad de resignificar a la adulta mayor como seres humanos y mujeres que siguen vigentes y capacitadas para desarrollar roles sociales productivos. Rey (2007) se interroga sobre cómo los cambios sociales y tecnológicos impactan el comportamiento y las prácticas comunicativas, a la vez que contribuyen a resignificar edades, géneros y roles sociales. Tal resignificación exige trabajar acerca de nuevas formas de relación entre las personas de todas las edades, que impliquen, además, integrar pasado, presente y futuro en el tema de la vejez, no solamente porque estamos en sociedades progresivamente envejecidas, sino porque se está transformando socialmente la imagen y el papel de las personas viejas (Red Latinoamericana de Gerontología, 2009).

\section{Recomendaciones}

Ante la naturalización de los estereotipos, resulta necesario un urgente cambio, porque son los que establecen las bases de la desigualdad misma y esto aplica tanto para los adultos mayores como para los conceptos de género.

En esta perspectiva, la educación, los medios y las tecnologías se convierten en denominadores comunes para colocarse a las órdenes de la geronto- 
logía-gerontagogía y la comunicación social, para contribuir a erradicar los estereotipos o imágenes negativas, que persisten en la sociedad con relación a los adultos mayores y poder apostar por una cultura más positiva del envejecimiento y la vejez para la población adulta mayor colombiana y mexicana. Hay que destacar las diferencias entre los adultos mayores, para reconocer sus derechos de manera equitativa y justa, puesto que (si no todos son iguales) no todos se deben concebir ni tratar igual. Es decir, hay que promover el aprendizaje diferenciado de los distintos roles que ocupa el adulto mayor en nuestra cotidianidad y en la sociedad.

Se sugiere que los productores de telenovelas reciban capacitación respecto a esta metodología, conocimiento sobre investigaciones que aborden temáticas de género y envejecimiento activo, así como la posibilidad de crear propuestas que impliquen un cambio de valores en la sociedad. También se sugiere estudiar sobre la demografía del envejecimiento a nivel nacional y mundial, para vislumbrar otras formas de hacer televisión y contribuir a una cultura positiva de la vejez a través del EE.

\section{Fuentes consultadas}

Amoros, C. (2005). Dimensiones de poder en la teoría feminista. Revista Internacional de Filosofia Política, 25, 11-34. https://www.redalyc.org/ pdf/592/59202501.pdf

Bandura, A. (1973). Aggression: A social learning analysis. Prentice-Hall.

Barker. K. (2007, Julio 1). Sex soap \& social change - The Sabido methodology. https://www.populationmedia.org/2007/08/09/sex-soap-social-change-the-sabido-methodology/

Barker, K. (2011). Sex, soap and social change: Theories underlyying the Sabido Methodology. En Population Media Center, Using the Media to Achieve Reproductive Health and gender equity (pp. 3-11). Population Media Center, UNFPA. https://31h07xhlls346a7ggo9psa1d-wpengine. netdna-ssl.com/wp-content/uploads/2014/11/UNFPA-English-webready-low-res.pdf 
Carpallo, S. (2018, Abril 5). Por qué las mujeres mayores de 50 deben tener pareja sexual más jóvenes (y no al revés). Dos estudios analizan los beneficios (y los riesgos) del sexo en edad avanzada. El País. https:// elpais.com/elpais/2018/03/31/buenavida/1522490375_671566.html

CNN Chile. (2018, Agosto 15). De los 25 países con tasas más altas de feminicidios, 14 son de América Latina. https://www.cnnchile.com/ mundo/de-los-25-paises-con-tasas-mas-altas-de-femicidios-14-sonde-america-latina_20180815

Departamento Administrativo Nacional de Estadística, DANE. (2018). Censo nacional de población y vivienda 2018 Colombia - ¿Cuántos somos? https:// www.dane.gov.co/index.php/estadisticas-por-tema/demografia-y-poblacion/censo-nacional-de-poblacion-y-vivenda-2018/cuantos-somos

El Universal. (2017, Mayo 8). El 27.8\% de las mujeres ejerce su maternidad sin pareja. https://www.eluniversal.com.mx/articulo/cartera/economia/2017/05/8/el-278-de-las-mujeres-ejerce-su-maternidad-sin-pareja

Fajardo-Ortíz, G., \& Olivares-Santos, R. (2008). Viejismo en el ambiente cotidiano. En V. Mendoza, M. Martínez, \& L. Vargas (Eds.), Viejismo: Prejuicios y estereotipos de la vejez (pp. 77-100). FES Zaragoza, UNAM. https://docplayer.es/78840586-Capitulo-3-viejismo-en-el-ambiente-cotidiano-el-vocablo-estereotipo-implica-una-idea-expresion-o-modelo-en-el-caso-de-la.html

Federación Iberoamericana de Asociaciones de Personas Adultas Mayores, FIAPAM. (2014, Diciembre 3). No a la violencia contra las mujeres adultas mayores. https://fiapam.org/no-a-la-violencia-contra-las-mujeres-adultas-mayores/

García, J., \& García, Q. (2015). El entretenimiento educativo en las telenovelas. Revista Internacional de Humanidades, 4 (1). http://journals. epistemopolis.org/index.php/humanidades/article/view/736/305

Igartua, J. (2005). Comunicación para la salud y sida: la aproximación educación-entretenimiento. Comunicar. Revista Cientifica de Comunicación y Educación, XIII(26), 35-42. https://doi.org/10.3916/C26-2006-06 
Infobae. (2019, Diciembre 2). Los feminicidios crecieron 111\% en los últimos cuatro años y 2019 amenaza con romper cifras récord. https://www. infobae.com/america/mexico/2019/12/02/los-feminicidios-crecieron111-en-los-ultimos-cuatro-anos-y-2019-amenaza-con-romper-cifrasrecord

Instituto Nacional de Estadística y Geografía, INEGI. (2015). Indicadores de población. https://www.inegi.org.mx/temas/estructura

Instituto Nacional de las Personas Adultas Mayores, INPAM. (2019, Junio 14). El maltrato en la vejez. https://www.gob.mx/inapam/articulos/elmaltrato-en-la-vejez

Jiménez, L. (2014, Diciembre 20). Método comparativo constante. http://dossiermalinally.blogspot.com/2014/12/metodo-comparativo-constante. html

Korotky, S., Blanc, L., \& Martín, H. (2003). Aportes a la preparación para una vida longeva. Publicación en homenaje a Lila Bezrukov de Villalba. Universidad Católica del Uruguay. https://www.gerontologia.org/ portal/archivosUpload/Abuelos_por_eleccion.pdf

Lizaur, B. (2014, Marzo 29). Ángeles sin alas: políticas del contenido en la telenovela mexicana, 1957-1997. http://www.mediosmejoresqueganenmas.org/especializados/angeles-sin-alas-politicas-del-contenido-en-la-telenovela-mexicana-1957-1997

Martín-Barbero, J., \& Muñoz, S. (1992). Televisión y melodrama. Tercer Mundo Editores.

Medina, M., \& Barrón, L. (2010). La telenovela en el mundo. Palabra Clave, 13(1), 77-97. https://palabraclave.unisabana.edu.co/index.php/palabraclave/article/view/1635/2154

Moreno, R., \& Pardo, L. (2018). La violencia contra las mujeres en Latinoamérica. Revista Foreing Affairs Latinoamerica. http://revistafal.com/ la-violencia-contra-las-mujeres-en-latinoamerica 
Rajewsky, I. (2005). Intermediality, Intertextuality, and Remediation: a literary perspective on intermediality. Intermédialités, 6, 43-64. https:// www.erudit.org/en/journals/im/2005-n6-im1814727/1005505ar

Red Latinoamericana de Gerontología. (2009). Hacia uma sociedade para todas las edades. Experiencias latino-americanas sobre relaciones intergeneracionales. https://www.yumpu.com/es/document/read/51870088/ hacia-una-sociedad-para-todas-las-edades-red-latinoamericana-

Revista Dinero. (2019, Agosto 17). Ser mujer sigue siendo una desventaja en el mercado laboral colombiano. https://www.dinero.com/pais/articulo/cuales-son-las-cifras-de-desempleo-de-las-mujeres-en-colombia/ 275660

Rey, G. (2007). Cultura, desarrollo y cooperación. Los remordimientos de la agenda cultural. Quórum. Revista de pensamiento iberoamericano, 17, 39-48. https://www.redalyc.org/pdf/520/52001705.pdf

Sabido, M. \& Jara, R. (1989). Marco teórico de las telenovelas mexicanas. Revista Chasqui Revista Latinoamericana de Comunicación, 31, 2430. https://revistachasqui.org/index.php/chasqui/article/view/827/869

Serret, E. (1998). Subordinación de la mujer e identidad femenina. Diferencias y conexiones. Revista Mexicana de Ciencias Politicas y Sociales, 43(174), 145-158. http://dx.doi.org/10.22201/ fcpys.2448492xe.1998.174.49132

Supermujer. (2015, Mayo 20). El estigma de las madres solteras. https://supermujer.net/elestigma-social-de-las-madres-solteras/

Tribuna Feminista. (2016, Julio 20). Ama de casa y dependiente del hombre: la publicidad perpetua estereotipos sexistas. https://tribunafeminista. elplural.com/2016/07/ama-de-casa-y-dependiente-del-hombre-el-rolperpetuo-de-las-mujeres-en-publicidad/

Tufte, T. (2005). Entertainment-education in development communication. Between marketing behaviours and empowering people. http://biblioteca.clacso.edu.ar/clacso/coediciones/20100824070831/14Chapter9.pdf 
Unisabana. (2014, Diciembre 10). Colombia, el país con más madres solteras en el mundo y donde la gente menos se casa, dice estudio. https:// www.unisabana.edu.co/menu-superior-1/saladeprensa/noticias/detalle-de-noticias/noticia/colombia-el-pais-con-mas-madres-solterasdel-mundo-y-donde-la-gente-menos-se-casa-dice-estudio

Van Dijk, T. (2002). Análisis crítico del discurso y el pensamiento social. Athenea Digital. Revista de Pensamiento e Investigación Social, 1, 18-24. https://doi.org/10.5565/rev/athenead/v1n1.22 